
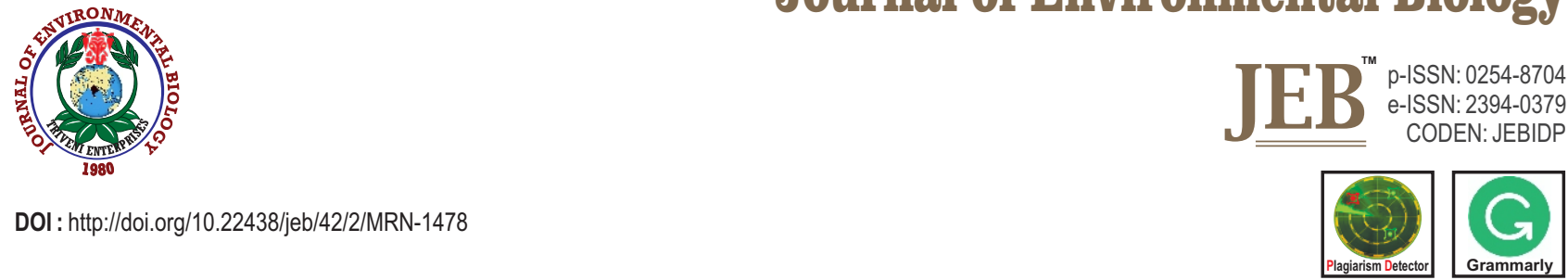

\title{
Role of dissolved oxygen on behavioural and stress response of golden mahseer, Tor putitora
}

\author{
A. Kalkhundiya, P.K. Bhatt, J. Chand and B.C. Pathak* \\ Department of Zoology, L.S.M. Govt. P.G. College, Pithoragarh-262 502, India \\ *Corresponding Author Email : bipinpathak11@gmail.com
}

\section{Abstract}

Aim: The study assessed the effect of different concentration of dissolved oxygen in Tor putitora, commonly known as Golden mahseer on physiological activities of juveniles regarding their growth performance, behavioural response and stress.

Methodology: Twenty-seven acclimatized fingerlings of Tor putitora were selected for the experiment, in which nine were exposed to each group of dissolved oxygen treatment (Natural, $6.76 \mathrm{mg} \mathrm{l}^{-1}$, low $4.81 \mathrm{mg} \mathrm{l}^{-1}$ and high, $10.20 \mathrm{mg} \mathrm{m}^{-1}$ ) in aquaria $(60 \times 30 \times 30) \mathrm{cm}$. The body weight $(\mathrm{g})$, cortisol concentration ( $\mathrm{ng} \mathrm{g}^{-1}$ ) and behaviour profile was assessed using the Ethovision XT-13 software (Noldus, Info Tech, Wageningen, The Netherlands).

Results: The average value of body weight $(\mathrm{g})$, cortisol concentration ( $\mathrm{ng} \mathrm{g}^{-1}$ ) and all behavioural profiles of Tor putitora showed a significant difference at $P<0.05$. The average concentration of cortisol was lower in high oxygen dissolved exposed juveniles as compared to other oxygen treatment groups.

Interpretation: High oxygen content in water bodies reduces the stress level and stereotyped behavioural responses of fishes. These novel data, on cognitive swimming pattern in Tor putitora, is quite important for enhancement of production and maintaining the fish health issues.

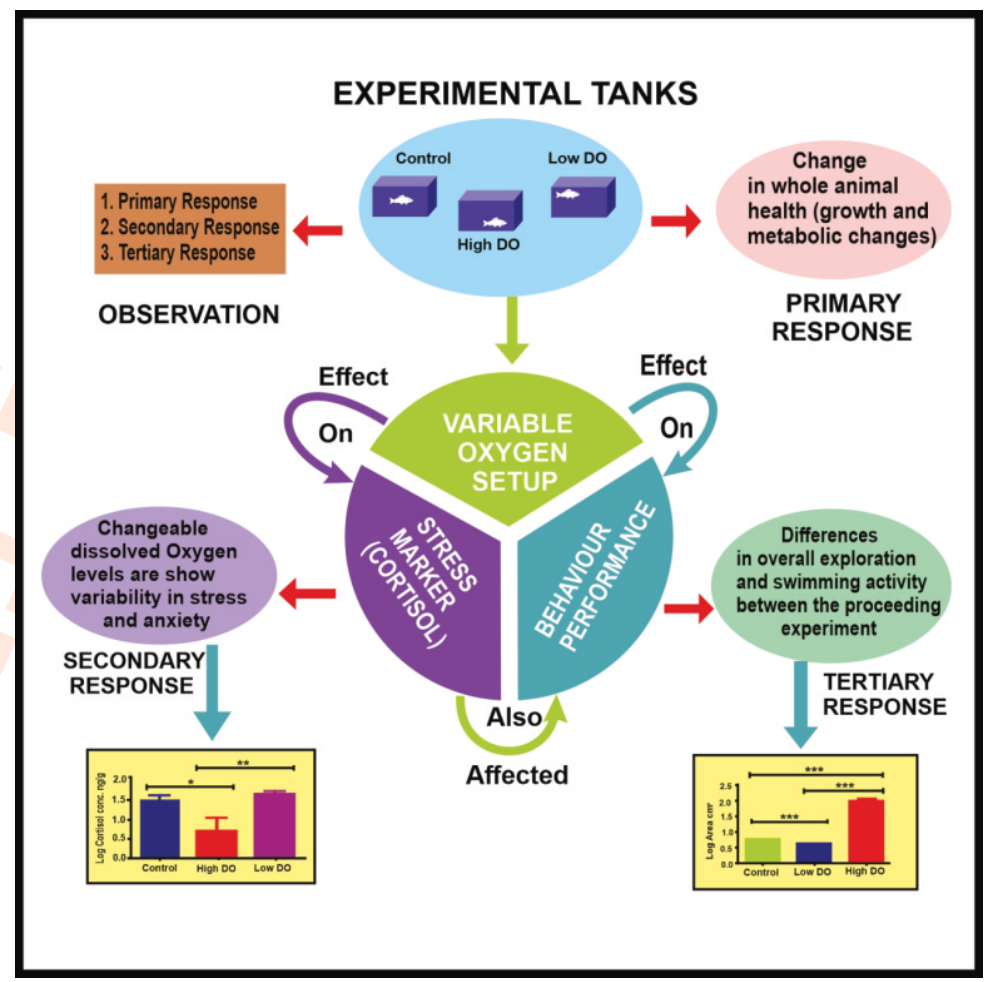

Key words: Behavioural profiling, Cortisol, Dissolved oxygen, Stress, Tor putitora

How to cite : Kalkhundiya, A., P.K. Bhatt, J. Chand and B.C. Pathak: Role of dissolved oxygen on behavioural and stress response of golden mahseer, Tor putitora. J. Environ. Biol., 42, 235-239 (2021). 


\section{Introduction}

Environmental parameters including dissolved oxygen play an important role in behavioural profiling and many vital activities of the fishes. Freshwater fishes are widely distributed in across the Trans Himalayan region and its snow-fed rivers among them Tor putitora is endemic to Asia. It usually greenish above light pink and silver-white below and fins are yellowish with lower part reddish in colour, the largest individuals ranged $271 \mathrm{~cm}$ total length weighing $54 \mathrm{~kg}$ (Everard and Kataria, 2011; Khan et al., 2017; Nautiyal et al., 2008; Nautiyal, 2014). Length of fish depends on water current, area visible, fluctuation, water depth and water quality, individual use of nutrition and high concentration of dissolved oxygen (Miller Neilan and Rose, 2014; Shen et al., 2008; Tyler et al., 2009). Dissolved oxygen concentration is key aspect of aquatic habitat from micro to higher bios quantity or quality control.

In this way dissolved oxygen helps in the survival of microorganism to higher aquatic life including fishes, it also regulates the density of the aquatic organism (Gan et al., 2013; Kaenel et al., 2000; Thetmeyer et al., 1999; Tran-Duy et al., 2012). Dissolved oxygen dynamics in lowland rivers is totally dependent on aquatic vegetation. The interaction of photosynthesis and respiration determines the dissolved oxygen level in aquatic habitats. A dissolved oxygen level is less than $2 \mathrm{~g} \mathrm{I}^{-1}$ is called hypoxia (Miller Neilan and Rose, 2014). In hypoxic conditioning fish become more stressful which can lead to serious health complications (Batiuk et al., 2009). If oxygen delivery was compromised, then tissue oxygen levels fall down and energy expenditure is grade up the anaerobic metabolism (Gan et al., 2013), which has been used as an indicator of the stress in hypoxic condition, that affected the swimming of fishes. In aerobic condition, swimming and exercises improves growth rate, muscle development, osmoregulation, and decreases cortisol levels and anxiety. Suspended sediment and low dissolved oxygen (hypoxia and hazard conditions) also affect fish physiology which can change the functional behaviour of fishes (Kjelland et al., 2015). The relation between aquatic environmental factors with trace behavioural platform (visual activity) of fishes, especially dissolved oxygen, growth rate and swimming parameters are still not studied in the hill stream fishes of India. Research upon endangered golden mahseer in relation to behaviour has not been studied till to this date. Therefore, the present study was designed to investigate the role of variable dissolved oxygen (DO) content upon performance of growth as well as behavioural profiling of Torputitora (fingerlings).

\section{Materials and Methods}

Collection of fish: Fingerlings of Tor putitora were collected from the river East Ramganga (29.54 $\left.\mathrm{N}, 80.104^{\prime} \mathrm{E}\right)$ in early morning hours. They were brought in fish bags to wet lab, at the Department of Zoology in L S M Govt P G College, Pithoragarh. Fish fingerlings were acclimatized for 60 days as described by Vaz et al., 2012.

Experimental conditions: Of these acclimatised fingerlings, twenty-seven were selected for the experiment. Out of which nine fingerlings were exposed to each group of dissolved oxygen content (natural, $6.76 \mathrm{mg} \mathrm{l}^{-1}$ ), (low $4.81 \mathrm{mg} \mathrm{I}^{-1}$ ) and (high, $\left.10.20 \mathrm{mg} \mathrm{ml}^{-1}\right)$ in the aquarium $(60 \times 30 \times 30) \mathrm{cm}$. The dissolved oxygen content was controlled by the oxygen air filter pump (air come from filter) in each group. To regulate higher and lower levels of the dissolved oxygen, tank effluent DO levels were maintained. This was also done by aerator joystick in fast and slow air flow mood (Abdel-Tawwab et al., 2015). The body weight of fishes was measured every week using a digital electronic balance $(0.001 \mathrm{~g})$. The daily dietary feed was adjusted $(0.400 \mathrm{~g}$ per tank) during the acclimation period. The same amount of feed was given to all treatment groups. The survival rate of fishes at the end of the experiment was also calculated as the no. of live fishes/total no. of fishes in terms of percentage. At the end of the experiment, all fishes were killed by using clove oil in order to find out the stress level of fishes. The whole samples were immediately stored in $-20^{\circ} \mathrm{C}$.

Monitoring water quality: The oxygen contents of tanks were measured throughout by the Winklers method (Helm et al., 2009) to maintain their approximate average value. Other parameters $(\mathrm{pH}$, temperature) were maintained constant throughout the experiment by $\mathrm{pH} / \mathrm{Tem}$ portable meter (Hanna instruments India Pvt. Ltd.).

Cortisol: The levels of cortisol were measured by using ELISA KIT (Enzyme-linked Immunosorbent Assay kit), following the protocols (Cachat et al., 2010). The completion of the ELISA protocols was with undeveloped 96 well plate (Tarson) with gentle shaking for $1 \mathrm{~min}$ and then the absorbance was taken by Elisa Plate Reader (Systronics) at $450 \mathrm{~nm}$. During the data processing, for proper validation of this cortisol data was performed simultaneously using duplication series of eight standard cortisol samples before any comparisons between the investigation samples were conducted. The assay quality was monitored using duplicate pool samples included on each plate. All samples were done on the same plate in parallel.

Behaviour: The behaviour of individual Tor putitora $(n=21)$ was also quantified with the help of Ethovision XT-13 software (Noldus, Wageningen, The Netherlands). Tor putitora were placed in open square tank $(60 \times 30 \times 30 \mathrm{~cm})$ under unobtrusive conditions. Their behaviour was recorded for a duration of 300 $\mathrm{sec}$ at the rate of 25 frame/sec using a digital Basler camera with pylon 4 Camera Software Suite 4.2.1.4845 which was connected with an administrated computer control. It analyses the normal or abnormal phenotypic movements of fish and converts into the regular numeric data forms.

Statistical analyses: One-way analysis of variance (ANOVA) was used to reveal variation in oxygen content, other water quality parameters. Changes in body weight, cortisol levels and behavioural data were assessed using one-way ANOVA. All statistical analyses were performed using by Graph Pad Prism.

\section{Results and Discussion}

In this study the average body weight of Tor putitora in the control group was $(3.10 \pm 0.03 \mathrm{~g})$ higher as compared to that 
higher dissolved oxygen ( $3.08 \pm 0.04 \mathrm{~g})$, as well as lower dissolved oxygen $(2.83 \pm 0.08 \mathrm{~g})$. The average value of body weight of fingerlings was analysed by using One Way Anova analysis showed a significant difference $\left(F_{12}=6.95\right.$ at $\left.P<0.009\right)$ followed by Newman-Keuls Mutiple Comparison test (Fig. 1a). The average concentration of cortisol in high oxygen dissolved exposed juveniles was (14.15 $\pm 5.68 \mathrm{ng} \mathrm{g}^{-1}$ ) as compared to control $\left(30.94 \pm 5.54 \mathrm{ng} \mathrm{g}^{-1}\right)$ and low oxygen exposed juveniles $\left(41.06 \pm 4.34 \mathrm{ng} \mathrm{g}^{-1}\right)$. There was a significant difference in the cortisol value among groups of juveniles of Tor putitora (one Way ANOVA, $F_{24}=8.50$ at $P<0.002$ ) (Fig. 1b). The growth of fingerling of Tor putitora was more in the high dissolved oxygen group than lower oxygen group. All water quality parameters such as temperature and $\mathrm{pH}$ were constant in all the groups.

The relation between the oxygen and growth performance of fishes was studied by (Abdel-Tawwab et al., 2014; Abdel-Tawwab et al., 2015). The data of dissolved oxygen content subjected to one way ANOVA analysis $\left(F_{8}=6.925 P<\right.$ 0.0001) followed by Tukey's Multiple Comparison test showed a significant difference at $P<0.05$. Survival rate were of control $(66.66 \%)$, low dissolved (88.88\%), and high dissolved oxygen (44\%). The other water quality parameters such as $\mathrm{pH}$, temperature were approximately similar to each other and there was no significant difference among them. The oxygen levels down due to any toxicant or either any decayed material, lower rushing water and vegetation in aquatic habitat. That effect on the brain in terms of their physical performance (growth and behavioural pattern). Swimming is an innate behavioural learning pattern. But some time until it would be highly affected by any stressor condition and it would also affect the growth rate of fishes. As in cases of rainbow trout effective stress (through cortisol marker) level responsible for growth performance (Fevolden et al., 2002; Quillet et al., 2014). Researchers have previously explored the relation between oxygen consumption and metabolic activity of fishes (Pichavant et al., 2000). The oxygen levels in the ecosystem of an organism affecting its routine behavioural activity. At low level of threshold, it elicits stress behaviours like as slow swimming activity, fast gill or opening mouth activity, low disease resistance detrimental effect upon the respiratory system. These also affect the aggressive behaviour activity in fishes. In this respect the movement duration (s) of fishes around the centre point of arena in the control group was (228.6 \pm 6.99$)$ as compare to low oxygen exposed group (226.8 \pm 13.78$)$ and high oxygen exposed group (277.8 \pm 8.06$)$.

The average behavioural scoring of all trial movement data was subjected to one-way ANOVA analysis $\left(F_{20}=5.865\right.$ at $P \leq$ 0.0109), followed by Tukey's Multiple Comparison test shows a significant difference at $P<0.05$. The average movement frequency of fishes around the centre point of arena were in the control (34.75 \pm 2.23$)$, low dissolved oxygen $(28.75 \pm 2.23)$ and high dissolved (18.40 \pm 6.76$)$. The average behavioural scoring of all trial movement frequency at the centre point of arena shows a significant difference $\left(F_{20}=4.997\right.$ at $\left.P \leq 0.0188\right)$, with following the Turkey multiple comparison test. The movement frequency is least around the centre point of arena in the high oxygen content group than other groups. Mostly the fishes were using their 'personality traits and movement characteristics' during their schooling behaviour (Tang and Fu, 2020). The duration (S) of movement around the centre point of arena explored area was maximum in the high dissolved oxygen content group as compared to other groups, indicating that the oxygen content plays an important role in the activity of the fishes. The different types of fish behavioural activity such as movement, average speed, exploration by the Zebrafish along the $\mathrm{X}$ axis in the arena was studied by using robotics as a source of artificial intelligence (Spinello et al., 2019). The normalised average area of exploration within the arena were in the control $\left(0.81 \pm 0.005 \mathrm{~cm}^{2}\right)$, low dissolved oxygen $\left(0.63 \pm 0.015 \mathrm{~cm}^{2}\right)$ and high dissolved oxygen $\left(2.02 \pm 0.01 \mathrm{~cm}^{2}\right)$. The area explored by the fishes during trial conditions showed a significant difference after the log transformation of subjected data (One Way ANOVA, $F_{2400}=4850$ at $\left.P<0.0001\right)$ the Tukey multiple comparison test. The post-hoc Turkey multiple comparison test shows a significant difference in both groups (Fig. 2). The novel tank explorative area was maximally explored by the high oxygen content group as compared to low oxygen content group. The immobility or not moving frequency and duration were less in the high oxygen content group as compared to the other groups. This indicates that the high dissolved oxygen environment is more favourable for the fishes as compared to others. Exploratory behaviour of fry of Tor putitora in the different artificial conditions were also

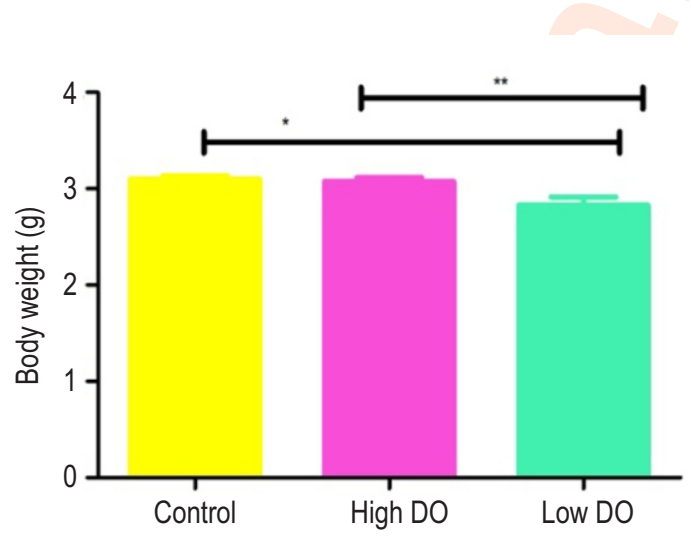

(a)

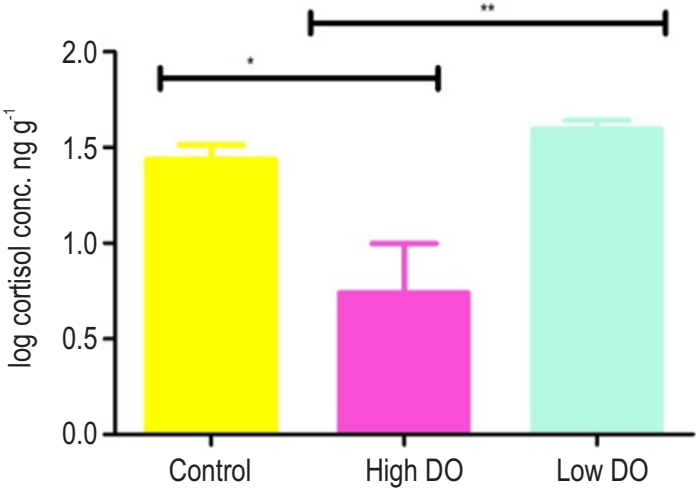

(b)

Fig. 1: (a) Average body weight (g) and (b) Cortisol level ( $\left.\mathrm{ng} \mathrm{g}^{-1}\right)$ in Tor putitora fish fingerlings exposed to high and low oxygen content groups. Values are Mean \pm S.E. 


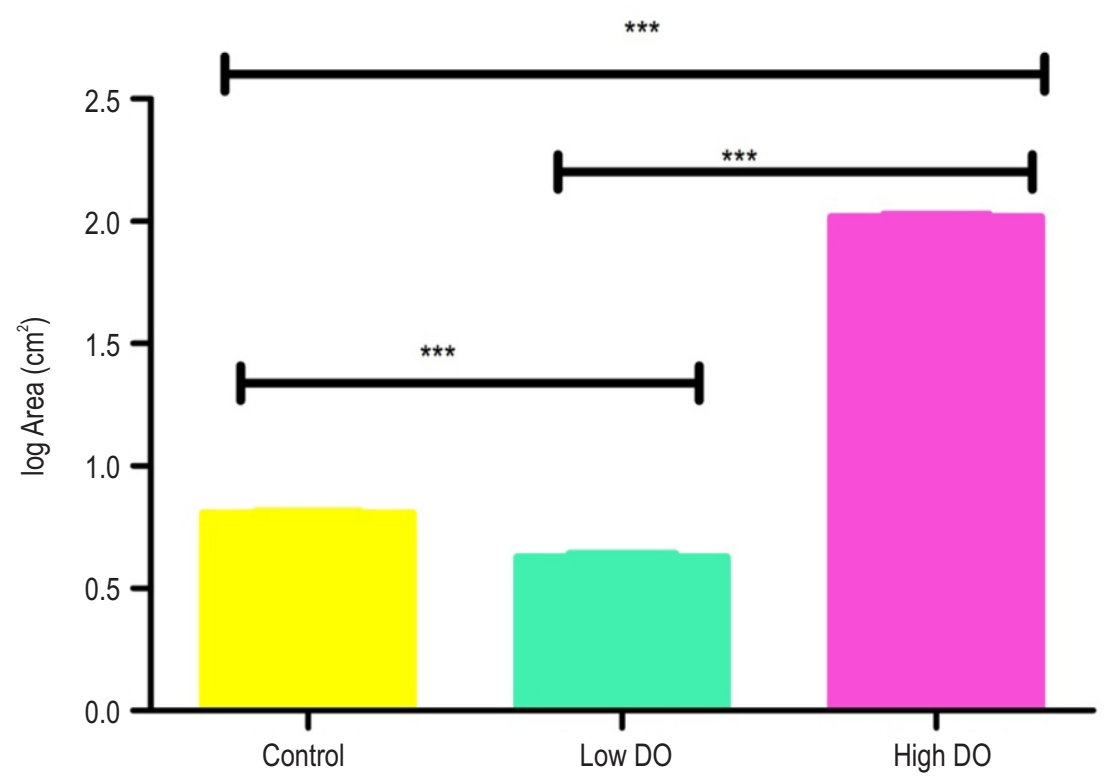

Fig. 2: Exploratory behaviour of Tor putitora fingerlings after exposure to oxygen content. Values are mean \pm S.E.

studied by Ullah et al. (2017). The aquatic vegetation in lowland rivers regulates the dissolved oxygen content by aquatic biota. With decreasing level of dissolved oxygen, fish gills ventilation frequency increases oxygen consumption in exposed fishes (Perry et al., 2009).

This is the first study of Tor putitora regarding variability, how oxygen level affected growth rate and behavioural responses. Growth of fingerling of Tor putitora was more in the high dissolved oxygen group than in others. The chronic marker of stress i.e. cortisol was less in the highly dissolved oxygen group members than in low and control groups. Such a study was done by (Welker et al., 2019) on the rainbow trout. They found that the high cortisol contents in low oxygen exposed fishes. According to (Castro et al., 2011) and Vandeputte et al. (2016). Atlantic salmon showed growth, as well as resistance to macro infection as well as good swimming performance with adequate dissolve oxygen content. On the other hand, the fishes subjected to the anaerobic condition changes the dynamic action with induced stress (Mette Remen et al., 2013; Remen et al., 2015). Concurrently with hypoxia situation, the metabolic rate (ATP production) decreases with high consumption of energy which may lead to more stress than under the normoxia situation (Bergheim et al., 2006; Richards, 2009). Stress increases blood glucose levels through activating either glycogenolysis or gluconeogenesis in order to enhance the catecholamine levels (Barth et al., 2007).

The ecology of aquatic organisms is affected by the level of oxygen in the medium. In order to cope low dissolved oxygen, fishes use the minimum metabolic energy for exporting and covered smaller area as compared to others. High oxygen content in the water bodies reduces the stress level of the fish and enhances their stereotypic behavioural responses. All these novel data on Tor putitora, are quite important for enhancing quality and quantity of production and maintaining the fish health related with swimming pattern. The hypoxia, normoxia and hyperoxia conditions studied here drive a significant difference in the growth performance as well as stereotypic behavioural performance of fingerling Tor putitora. This study provides useful knowledge for stereotypic behavioural aspect of Tor putitora in relation to their conservation and management.

\section{Acknowledgments}

The present study was funded by the Department of Science and Technology, Govt of India under the Young Scientist scheme (DST/YSS/2015/000538). The authors are also thankful to the principal for providing the facility in the college.

\section{Add-on Information}

Authors' contribution: A. Kalkhundiya: Sampling, works on Experiments, writing the paper and excute the experiment; P.K. Bhatt: Helps in sampling and infrastructral facility set up; J. Chand: Helps in experiments; B.C. Pathak: Designing, monitoring the experiments, writing the paper, guiding the students in every step, proofreading, statistical analysis, etc.

Research content: The research content is original and has not been published elsewhere

\section{Ethical approval: NotApplicable}

Conflict of interest: The authors declare that there is no conflict of interest.

\section{Data from other sources: NotApplicable}

Consent to publish: All authors agree to publish the paper in Journal of Environmental Biology. 


\section{References}

Abdel-Tawwab, M., A.E. Hagras, H.A.M. Elbaghdady and M.N. Monier: Dissolved oxygen level and stocking density effects on growth, feed utilization, physiology, and innate immunity of Nile tilapia, Oreochromis niloticus. J. Appl. Aquacul., 26, 340-355 (2014).

Abdel-Tawwab, M., A.E. Hagras, H.A.M. Elbaghdady and M.N. Monier: Effects of dissolved oxygen and fish size on Nile tilapia, Oreochromis niloticus (L.): Growth performance, whole-body composition, and innate immunity. Aquacul. Int., 23, 1261-1274 (2015).

Barth, E., G. Albuszies, K. Baumgart, M. Matejovic, U. Wachter, J. Vogt, P. Radermacher and E. Calzia: Glucose metabolism and catecholamines. Critic. Care Medic., 35, S508-S518 (2007).

Batiuk, R.A., D.L. Breitburg, R.J. Diaz, T.M. Cronin, D.H. Secor and G. Thursby: Derivation of habitat-specific dissolved oxygen criteria for Chesapeake Bay and its tidal tributaries. J. Experim. Marine Biol. Ecol., 381, S204-S215 (2009).

Bergheim, A., M. Gausen, A. Næss, P.M. Hølland, P. Krogedal and V. Crampton: A newly developed oxygen injection system for cage farms. Aquacul. Engine., 34, 40-46 (2006).

Cachat, J., A. Stewart, L. Grossman, S. Gaikwad, F. Kadri, K.M. Chung, N. Wu, K. Wong, S. Roy and C. Suciu: Measuring behavioral and endocrine responses to novelty stress in adult zebrafish. Nature Protocols, 5, 1786-1799 (2010)

Castro, V., B. Grisdale-Helland, S.J. Helland, T. Kristensen, S.M. Jørgensen, J. Helgerud, G. Claireaux, A.P. Farrell, A. Krasnov and $\mathrm{H}$. Takle: Aerobic training stimulates growth and promotes disease resistance in Atlantic salmon (Salmo salar). Compar. Bioche. Physiol. PartA: Molec. Integra. Physiol., 160, 278-290 (2011).

Everard, M. and G. Kataria: Recreational angling markets to advance the conservation of a reach of the Western Ramganga river, India. Aquatic Conservation: Marine and Freshwater Ecosystems, 21, 101-108(2011)

Fevolden, S.E., K.H. Røed and K.T. Fjalestad: Selection response of cortisol and lysozyme in rainbow trout and correlation to growth. Aquaculture, 205, 61-75(2002)

Gan, L., Y.J. Liu, L.X. Tian, Y.R. Yue, H.J. Yang, F.J. Liu, Y.J. Chen and G.Y. Liang: Effects of dissolved oxygen and dietary lysine levels on growth performance, feed conversion ratio and body composition of grass carp, Ctenopharyngodon idella. Aquacul. Nutrit., 19, 860-869 (2013).

Helm, I., L. Jalukse, M. Vilbaste and I. Leito: Micro-Winkler titration method for dissolved oxygen concentration measurement. Analyt. Chimi. Acta, 648, 167-173 (2009).

Kaenel, B.R., H. Buehrer and U. Uehlinger: Effects of aquatic plant management on stream metabolism and oxygen balance in streams. Freshwater Biol., 45, 85-95 (2000).

Khan, K.U., A. Zuberi, S. Nazir, I. Ullah, Z. Jamil and H. Sarwar: Synergistic effects of dietary nano selenium and vitamin $\mathrm{C}$ on growth, feeding, and physiological parameters of mahseer fish (Tor putitora). Aquacul. Rep., 5, 70-75 (2017).

Kjelland, M.E., C.M. Woodley, T.M. Swannack and D.L. Smith:A review of the potential effects of suspended sediment on fishes: Potential dredging-related physiological, behavioral, and trans-generational implications. Environ. Syst. Decis., 35, 334-350 (2015)

Miller, R. Neilan and K. Rose: Simulating the effects of fluctuating dissolved oxygen on growth, reproduction, and survival of fish and shrimp. J. Theore. Biol., 343, 54-68 (2014).

Nautiyal, P., A.F. Rizvi and P. Dhasmanaa: Life-hiistory traits and decadal trends in the growth parameters of golden mahseer Tor putitora
(Hamilton 1822) from the Himalayan stretch of the Ganga river system. Turki. J. Fisher. Aqu. Sci., 8, 125-132 (2008).

Nautiyal, P.: Review of the art and science of Indian Mahseer (game fish) from nineteenth to twentieth century: Road to extinction or conservation? Proceedings of the National Academy of Sciences, India Section B: Biol. Sci., 84, 215-236 (2014).

Perry, S.F., M.G. Jonz and K.M. Gilmour: Oxygen sensing and the hypoxic ventilatory response. Fish Physiol., 27, 193-253 (2009).

Pichavant, K., J.P.L. Ruyet, N.L. Bayon, A. Sévère, A.L. Roux, L. Quéméner, V. Maxime, G. Nonnotte and G. Boeuf: Effects of hypoxia on growth and metabolism of juvenile turbot. Aquaculture, 188, 103-114 (2000).

Quillet, E., F. Krieg, N. Dechamp, C. Hervet, A. Bérard, P.L. Roy, R. Guyomard, P. Prunet and T.G. Pottinger: Quantitative trait loci for magnitude of the plasma cortisol response to confinement in rainbow trout. Animal Gene., 45, 223-234 (2014).

Remen, M., M. Nederlof, O. Folkedal, G. Thorsheim, A. Sitjà-Bobadilla, J. Pérez-Sánchez, F. Oppedal and R. Olsen: Effect of temperature on the metabolism, behaviour and oxygen requirements of Sparus aurata. Aquacu. Environ. Interact., 7, 115-123 (2015).

Remen, M., F. Oppedal, A.K. Imsland, R.E. Olsen and T. Torgersen: Hypoxia tolerance thresholds for post-smolt Atlantic salmon: Dependency of temperature and hypoxia acclimation. Aquaculture, 416, 41-47 (2013).

Richards, J.G.: Metabolic and molecular responses of fish to hypoxia. Fish Physiol., 27, 443-485 (2009).

Shen, J., T. Wang, J. Herman, P. Mason and G.L. Arnold: Hypoxia in a coastal embayment of the chesapeakebay: A model diagnostic study of oxygen dynamics. Estuar. Coa., 31,652-663 (2008).

Spinello, C., Y. Yang, S. Macrì and M. Porfiri: Zebrafish adjust their behavior in response to an interactive robotic predator. Front Robot. Al, 6, 1-14 (2019).

Tang, J.Y. and S.J. Fu: The relationship between personality and the collective motion of schooling fish. J. Ethol., 38, 333-341 (2020).

Thetmeyer, H., U. Waller, K.D. Black, S. Inselmann and H. Rosenthal: Growth of European sea bass (Dicentrarchus labrax L.) under hypoxic and oscillating oxygen conditions. Aquaculture, 174, 355-367(1999).

Tran-Duy, A., A.A.V. Dam and J.W. Schrama: Feed intake, growth and metabolism of Nile tilapia (Oreochromis niloticus) in relation to dissolved oxygen concentration. Aquacul. Res., 43, 730-744(2012).

Tyler, R.M., D.C. Brady and T.E. Targett: Temporal and spatial dynamics of diel-cycling hypoxia in estuarine tributaries. Estua. Coa., 32, 123-145 (2009).

Ullah, I., A. Zuberi, K.U. Khan, S. Ahmad, P.O. Thörnqvist and S. Winberg: Effects of enrichment on the development of behaviour in an endangered fish mahseer (Tor putitora). Appl. Animal Behavi. Sci., 186, 93-100 (2017)

Vandeputte, M., J.D. Porte, B. Auperin, M. Dupont-Nivet, A. Vergnet, C. Valotaire, G. Claireaux, P. Prunet and B. Chatain: Quantitative genetic variation for post-stress cortisol and swimming performance in growth-selected and control populations of European sea bass (Dicentrarchus labrax). Aquaculture, 455, 1-7. (2016).

Vaz, M.C.M., T.A.P. Rocha-Santos, R.J.M. Rocha, I. Lopes, R. Pereira, A.C. Duarte, P.J. Rubec and R. Calado: Excreted thiocyanate detects live reef fishes illegally collected using cyanide-A non-invasive and non-destructive testing approach. PLOS ONE, 7, e35355 (2012).

Welker, T.L., K. Overturf and J. Abernathy: Effect of aeration and oxygenation on growth and survival of rainbow trout in a commercial serial-pass, flow-through raceway system. Aquacul. Rep., 14, 100194 (2019). 